\title{
Can Liver Imaging for Focal Lesions be Limited with Only Diffusion- Weighted Sequences in Patients without Known Malignancy?
}

\author{
Sertan Gezgin (1), Murat Kocaoğlu (1) \\ Department of Radiology, Near East University School of Medicine, Mersin, Turkey
}

ORCID IDs of the authors: S.G. 0000-0002-5936-5392; M.K. 0000-0002-4674-8634.

Cite this article as: Gezgin S, Kocaoğlu M. Can Liver Imaging for Focal Lesions be Limited with Only Diffusion-Weighted Sequences in Patients without Known Malignancy?. Cyprus J Med Sci 2019; 4(I): 43-5I.

\section{BACKGROUND/AIMS}

Our purpose is to investigate whether the diffusion-weighted imaging (DWI) can be used as an initial and decisive sequence to shorten liver magnetic resonance imaging (MRI) study, rather than being complementary to conventional sequences especially in patients without known malignancy.

\section{MATERIAL and METHODS}

The MRI characteristics of 105 focal liver lesions (FLLs) were classified as benign or malignant by visually assessing the DWI features, and the lesions were compared with a complete liver MRI protocol. Hyperintensity or isointensity of a lesion in apparent diffusion coefficient map by visual assessment was accepted as unrestricted diffusion and benignity, while hypointensity in any part of a lesion was accepted as restricted diffusion and malignancy. Specificity, sensitivity, positive predictive value, negative predictive value, and accuracy of DWI were calculated.

\section{RESULTS}

The visual assessment of DWI alone had $74.29 \%$ sensitivity, $94.29 \%$ specificity, $86.67 \%$ positive predictive value, $88.00 \%$ negative predictive value, and $87.62 \%$ accuracy in differentiating malignant lesions from the benign ones. In 28 of 32 patients without malignancy, DWI results were in concordance with the final diagnosis of benign lesions. The misinterpreted lesions in these patients were three abscesses and a hemorrhagic adenoma.

\section{CONCLUSION}

Visual DWI characteristics of FLLs in patients without known malignancy can accurately classify the lesions as benign or malignant. In appropriately selected patients, a liver MRI examination can be completed with only DWI, resulting decrease in time and cost related to intravenous contrast media usage.

Keywords: MRI, diffusion-weighted imaging, liver, tumor, intravenous contrast, abdomen

\section{INTRODUCTION}

Characterizing focal liver lesions (FLLs) is an important part of the radiology practice. Ultrasonography (US), computed-tomography (CT), and magnetic resonance imaging (MRI) can be used for this; however, intravenous (iv) contrast-enhanced liver MRI has the highest accuracy. Relatively costly and time-consuming conventional abdomen MRI requires the use of iv contrast agents. Diffusion-weighted imaging (DWI) has long been used as a complementary sequence in abdominal MRI. DWI is a noninvasive imaging method based on the Brownian motion of water molecules. Diffusion of water molecules is quantitatively expressed by apparent diffusion coefficient (ADC). Low ADC values are associated with high cellularity and viscosity suggesting malignancy or abscess, respectively (I). DWI has begun to play an important role in the detection and characterization of FLLs in conjunction with evolving hardware and software technologies (2). Many studies investigate the role of DWI in discrimination of malignant abdominal tumors from the benign ones. Most of these studies compare quantitative ADC values (3-9). A systematic database review study conducted by Vermoolen et al. (10) reported that mean ADC values of malignant lesions and benign lesions ranged from $0.86 \pm 0.11$ to $1.52 \pm 0.55 \times 10^{-3} \mathrm{~mm}^{2} / \mathrm{s}$ and $1.94-2.86 \times 10^{-3} \mathrm{~mm}^{2} / \mathrm{s}$, respectively. Bharwani et al. (II) reported that the threshold of $1.7 \times 10^{-3} \mathrm{~mm}^{2} / \mathrm{s} A D C$ value had a significantly higher diagnostic sensitivity and specificity in differen- 
tiation of malignant and benign FLLs. In an another study that examined $215 \mathrm{FLLs}$, the optimal ADC threshold value generating $79 \%$ sensitivity and $82.6 \%$ specificity was found to be $1.25 \times 10^{-3} \mathrm{~mm}^{2} / \mathrm{s}(4)$. As shown in the abovementioned studies, the wide range of $A D C$ values can be because of scanners and the b-values. A group of researchers compared visual evaluation of the DWI and ADC maps with measured ADC values in FLLs, and they found high sensitivity and accuracy rates of visual assessment in both adult and pediatric abdominal tumors $(12,13)$. We hypothesized that beginning the liver imaging with DWI and visual assessment of its results eliminates an iv contrast-enhanced abdominal MRI protocol and decreases time and cost. Our purpose is to investigate whether the DWI can be used as an initial and decisive sequence to shorten liver MRI study, rather than being complementary to conventional sequences especially in patients without known malignancy.

\section{MATERIAL and METHODS}

\section{Patients}

Ethics committee approval was received for this study from Near East University Ethics Committee for Scientific Researches (Approval Date: 04.26.2018). In total, 213 upper abdominal MRI studies performed in our department between January 2016 and February 2018 were retrospectively evaluated. FLLs were found in 65 patients. Patients without known primary malignancy were referred to MRI examination for lesions determined in US or in CT examination, while patients with known primary malignancy were referred for screening or follow-up. Institutional review board approval was obtained for this retrospective study. FLLs smaller than I $\mathrm{cm}$, non-iv contrast studies, ADC map with motion or pulsation artifacts, and cases with nine or more liver lesions were excluded. Twelve of these patients were excluded because of lack of a contrast-enhanced study or an artifact-free ADC map. Three patients were excluded for having nine or more lesions. Only the first MRI study of a patient was included if they had multiple. Finally, 105 FLLs of 50 patients were included in the statistical analysis.

\section{MRI Protocol}

The MRI studies were carried out with a I.5-T MR scanner (Magnetom Aera, Siemens Healthcare, Erlangen, Germany). The standard imaging protocol included axial and coronal T2-weighted half-Fourier acquisition single-shot turbo spin echo (HASTE) sequences [repetition time (TR)/echo time (TE), 1200/91 ms; flip angle (FA), $169^{\circ}$; slice thickness (THK), $6 \mathrm{~mm}$; and number of excitations (NEX), l], axial fat-saturated T2-weighted HASTE sequence (TR/TE, 1200/94 ms; FA, $160^{\circ}$; THK, $6 \mathrm{~mm}$; and NEX, I), axial fat-saturated Tl-weighted fast low-angle shot (FLASH) sequence (TR/TE, 126/2.38 $\mathrm{ms}$; FA, $70^{\circ}$; THK, $6 \mathrm{~mm}$; and NEX, I), axial in-phase and opposed-phase TI-weighted FLASH sequences (TR/TE, II9/4.76 and $2.38 \mathrm{~ms}$, respectively; $\mathrm{FA}, 70^{\circ}$; THK, $6 \mathrm{~mm}$; and NEX, I), axial T2 and heavily T2-weighted HASTE sequence (TR/ $\mathrm{TE}, 1600 / 118$ and $445 \mathrm{~ms}$, respectively; FA, 157 ; THK, $6 \mathrm{~mm}$; and NEX, I), pre-contrast axial, fat-saturated TI-weighted volumetric interpolated breath-hold examination (VIBE) se- quence (TR/TE, 4.36/I.91 ms; FA, $10^{\circ}$; THK, $4 \mathrm{~mm}$; and NEX, I) and contrast-enhanced fat-saturated TI weighted VIBE sequences with same parameters at $30 \mathrm{~s}$ (arterial phase), $60 \mathrm{~s}$ (portal phase), and $150 \mathrm{~s}$ (venous phase) after injection of 0.1 $\mathrm{mmol} / \mathrm{kg}$ of gadoterate meglumine (Dotarem; Guerbet Group, France) bolus tracked visually by a real-time sequence, and a post-contrast axial Tl-weighted fat-saturated FLASH sequence at $300 \mathrm{~s}$ (late venous phase) after the injection. Diffusion-weighted images were obtained in axial plane with b-values of 50,400 , and $800 \mathrm{~s} / \mathrm{mm}^{2}$. Respiratory-triggered single-shot echo-planar images had these parameters: TR/ $\mathrm{TE}, 8000 / 6 \mathrm{lms}$ F $\mathrm{FA}, 90^{\circ}$; THK, $6 \mathrm{~mm}$; NEX, 3. The ADC maps were automatically created.

\section{MRI Analysis}

Histopathologic results or clinical and radiographic follow-up and typical imaging findings were accepted as reference standard. A radiologist with more than 10 years of experience in abdominal imaging read the whole data for each patient including physical examination findings, medical history, all MRI sequences, findings in other modalities (CT, US), pathology reports, and follow-up imaging findings to classify the lesions as malignant or benign. Lesions with peripheral globular contrast enhancement in the arterial phases and being hyperintense in the late venous phases compared to the normal liver parenchyma were evaluated as hemangioma (14). Lesions with peripheral rim-type contrast enhancement and having different enhancement pattern from normal liver parenchyma in patients with known primary tumors were evaluated as typical metastasis $(15,16)$. The diagnoses of metastases were also confirmed by decrease in size in patients receiving chemotherapy and increase in size in untreated patients who have follow-up imaging. Lesions being hyperintense on T2-weighted images and showing no contrast enhancement were evaluated as cysts (16). Lesions being mildly hypointense to moderately hyperintense on Tl-weighted images, mildly hyperintense on T2-weighted images, showing homogeneous enhancement in the arterial phases, and becoming nearly isointense in venous phases were evaluated as adenomas $(16,17)$. Lesions with heterogeneous internal structure and rapid contrast enhancement in the arterial phases and wash-out in venous phases were interpreted as hepatocellular carcinoma (HCC) (16-18). Pathological diagnoses of HCCs were also present. The abscesses showed peripheral enhancement of capsules and central restriction of diffusion in the ADC maps (19). Abscess material was evacuated with percutaneous drainage from two lesions. Transient hepatic attenuation differences (THAD) were found in a patient who showed wedge-shaped focal areas of hyperintensity in arterial phase and isointensity to normal liver in other phases and sequences and did not have mass effect (20). A lesion without a mass effect, showing signal drop-out in opposed-phase Tl-weighted sequence and similar contrast enhancement compared to normal liver parenchyma was diagnosed as focal fatty infiltration $(21,22)$.

An another radiologist with six years of experience in general radiology interpreted only the diffusion-weighted and $A D C$ images of the patients who were included in the study, and 
classified the lesions as being benign or malignant. He was blinded to the data and images other than DWIs and ADC maps. As in previous studies, hyperintensity or isointensity of a lesion in ADC map by visual assessment was accepted as unrestricted diffusion and benignity, whereas hypointensity in any part of a lesion was accepted as restricted diffusion and malignancy $(13,23)$.

\section{Statistical Analysis}

Diagnostic performance of DWI-alone interpretation was made by identifying true benign, false benign, true malignant, and false malignant lesions. Specificity, sensitivity, positive predictive value, negative predictive value, and accuracy were calculated from these results.

\section{RESULTS}

Eighteen of the patients included into the study had at least one known primary malignancy. Thirty-two of the patients did not have any known history of malignancy. Among the patients included in statistical analysis, 13 had malignant and

\begin{tabular}{lcccc|}
\hline TABLE I. Distribution of the lesions and patients according to the \\
diagnosis and counts of total lesions and patients \\
Type of lesion & $\begin{array}{c}\text { Number of } \\
\text { lesions }\end{array}$ & $\begin{array}{c}\text { Number of } \\
\text { patients }\end{array}$ & $\begin{array}{c}\text { Number of } \\
\text { patients } \\
\text { with known } \\
\text { malignancy }\end{array}$ & $\begin{array}{c}\text { Number of } \\
\text { patients } \\
\text { without known } \\
\text { malignancy }\end{array}$ \\
\hline Hemangioma & 47 & 23 & 4 & 19 \\
Metastasis & 32 & 11 & 11 & 0 \\
Cyst & 10 & 7 & 1 & 6 \\
Adenoma & 7 & 3 & 1 & 2 \\
HCC & 3 & 2 & 1 & 1 \\
Abscess & 3 & 2 & 0 & 2 \\
THAD & 2 & 1 & 0 & 1 \\
$\begin{array}{l}\text { Focal fatty } \\
\text { infiltration }\end{array}$ & 1 & 1 & 0 & 1 \\
Total & 105 & 50 & 18 & 32 \\
\hline $\begin{array}{l}\text { HCC: hepatocellular carcinoma; THAD: Transient hepatic attenuation } \\
\text { differences }\end{array}$ &
\end{tabular}
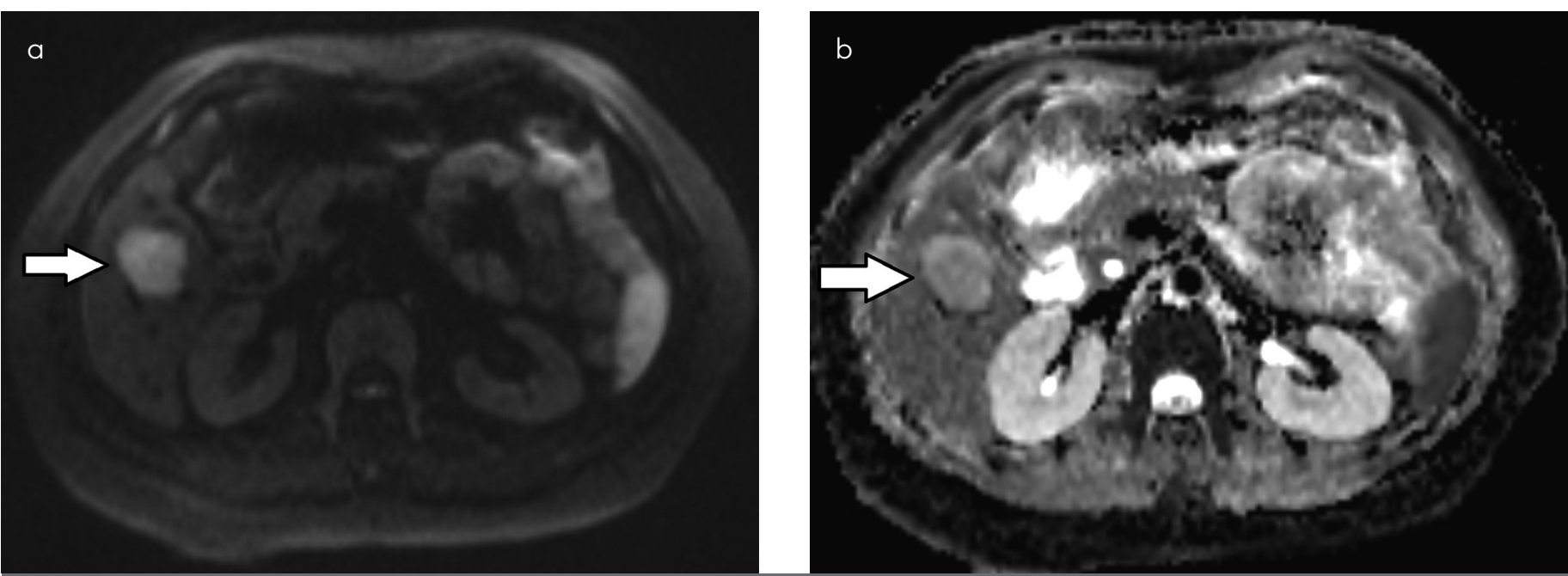

FIGURE I. a, b. A hemangioma in the right liver lobe. The lesion is hyperintense both on the diffusion-weighted image (a) with b value of $800 \mathrm{~s} /$ $\mathrm{mm}^{2}$ and on the ADC map (b)
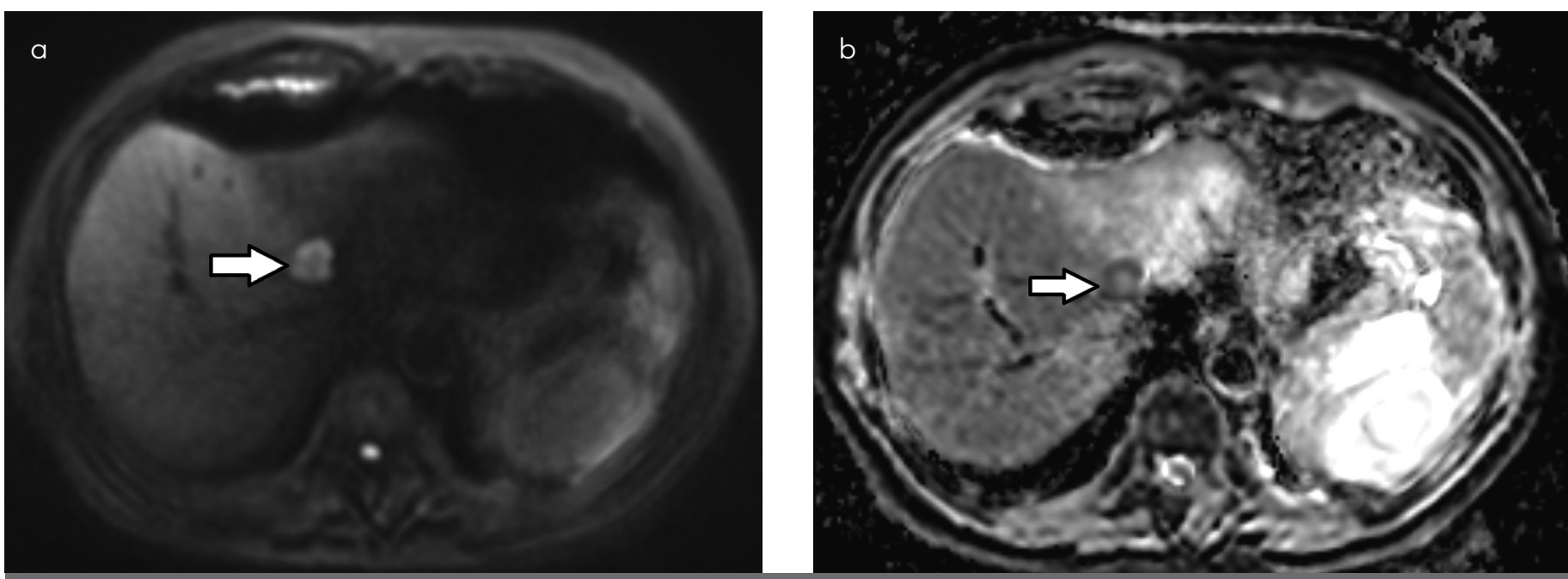

FIGURE 2. a, b. The periphery of a metastasis is seen hyperintense on b800 (a) and hypointense on ADC map (b) 

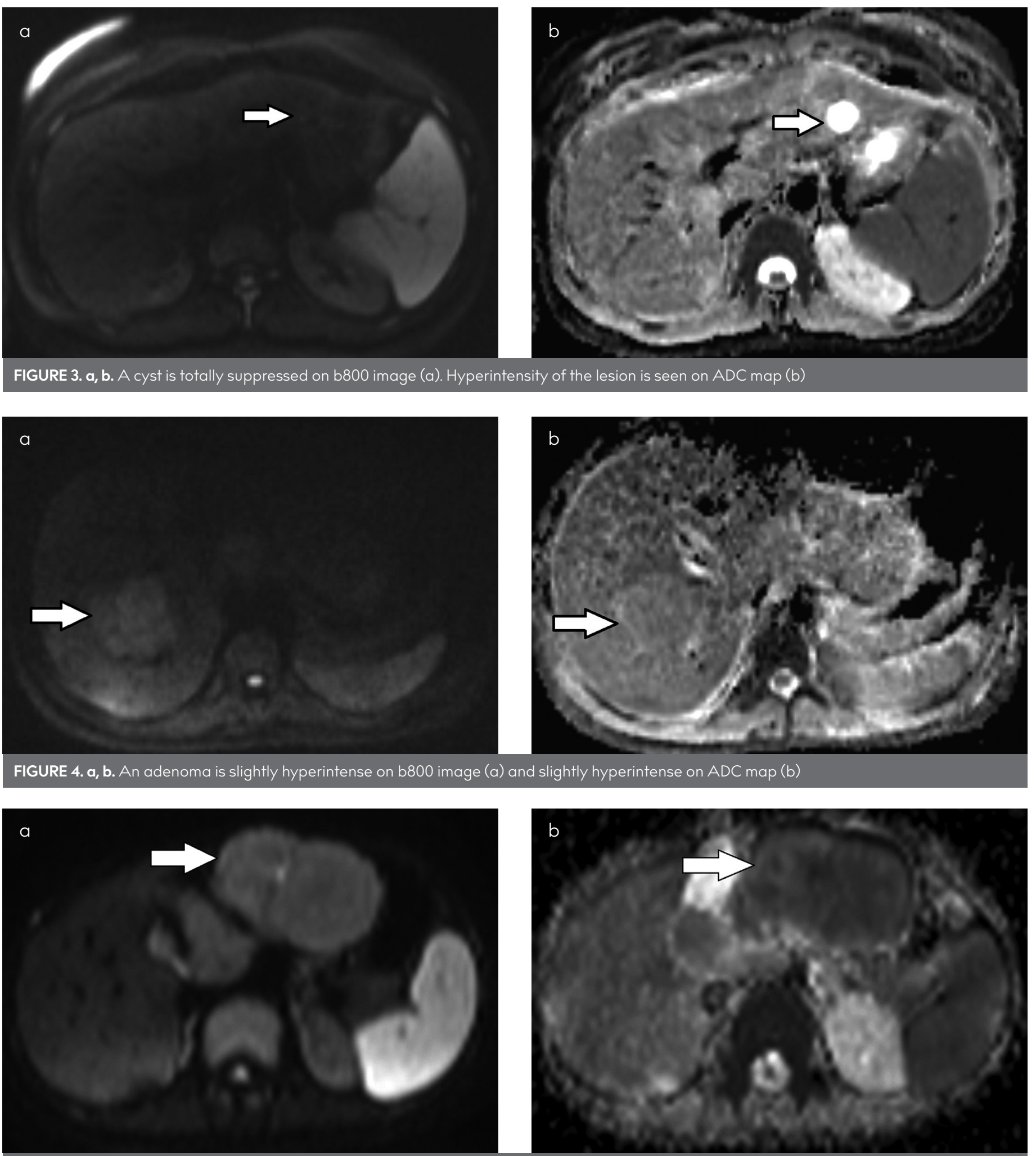

FIGURE 5. a, b. A fibrolamellar HCC located in the left liver lobe shows restriction of diffusion on b800 image (a). The lesion is hypointense on $\mathrm{ADC}$ map (b) compared to normal liver parenchyma

37 had benign lesions in MRI scans. The average age of patients with and without known primary malignancy was 58.3 (range 30-81) years and 49.4 (range 16-86) years, respectively. There were 32 female and 18 male patients. Eleven female patients had known malignancy, and seven had malignant liver lesions. Seven male patients had known malignancy, and six had malignant liver lesions. Number of lesions included in statistical analysis was 105. None of the patients had both malignant and benign FLLs. The average number of benign and malignant lesions in a liver was 1.89 (range I-6) and 2.69 (range 1-6), respectively. Most common lesions were hemangiomas and metastases (Table I). The DWI and ADC features 
TABLE 2. Signal characteristics of the lesions in the DWI-800 and ADC maps. ( $\uparrow$ : hyperintense, $\uparrow:$ mildly hyperintense, - : isointense, $\downarrow:$ hypointense). Numbers in the boxes are the count of lesions

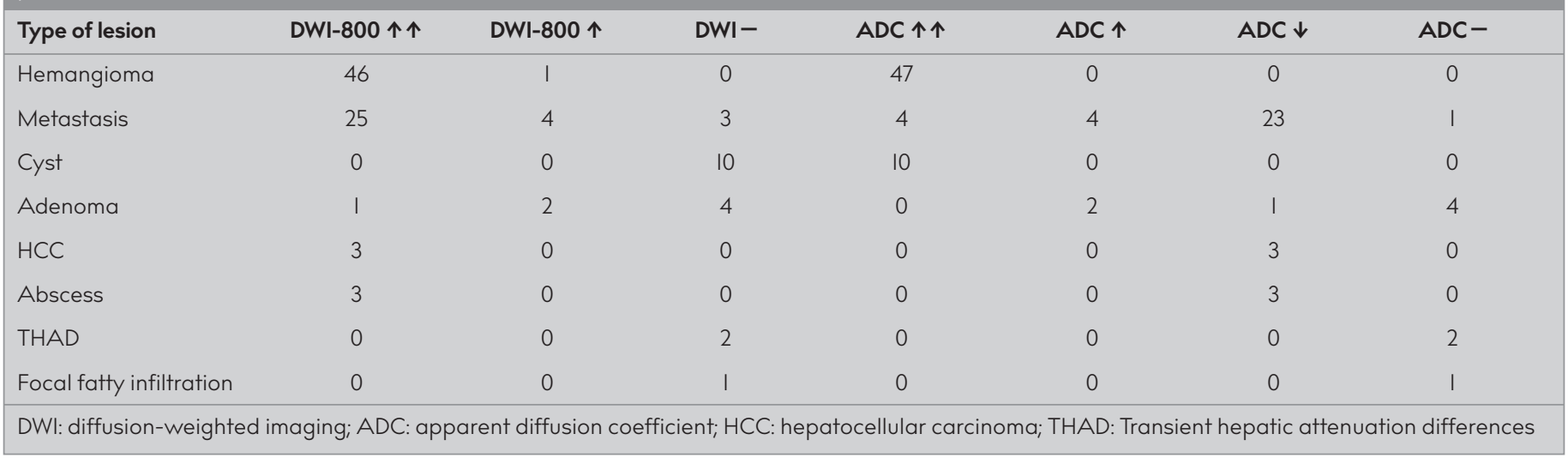

\begin{tabular}{|c|c|c|c|c|}
\hline & & \multicolumn{3}{|c|}{ Reference standard } \\
\hline & & Benign & Malignant & Total \\
\hline \multirow[t]{3}{*}{ DWI evaluation } & Benign & 66 & 9 & 75 \\
\hline & Malignant & 4 & 26 & 30 \\
\hline & Total & 70 & 35 & 105 \\
\hline
\end{tabular}

\begin{tabular}{|c|c|c|c|c|}
\hline & & \multicolumn{3}{|c|}{ Reference standard } \\
\hline & & Benign & Malignant & Total \\
\hline \multirow[t]{3}{*}{ DWI evaluation } & Benign & 52 & 0 & 52 \\
\hline & Malignant & 4 & I & 5 \\
\hline & Total & 56 & 1 & 57 \\
\hline
\end{tabular}
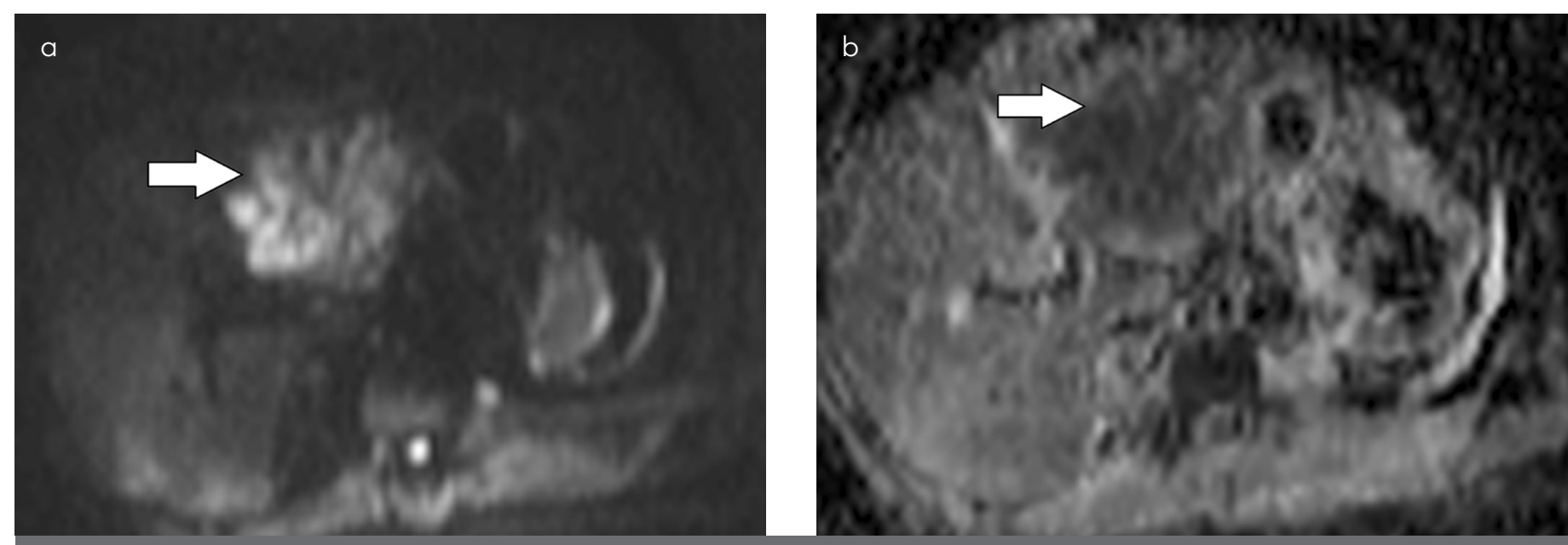

FIGURE 6. a, b. An abscesses in the left liver lobe of a patient shows restriction of diffusion on b800 image (a). The lesion is hypointense on ADC map (b) compared to normal liver parenchyma

of common lesions are demonstrated in Figure I-5. All the hemangiomas and cysts were hyperintense in the ADC maps. The cysts were isointense, and the hemangiomas were either hyperintense or mildly hyperintense in the diffusion-weighted images with b value of $800 \mathrm{~s} / \mathrm{mm}^{2}$ (DWI-800). Except one, lesions evaluated as adenomas were seen as isointense or mildly hyperintense in the ADC maps and in the DWI-800. All of the HCCs showed hypointensity in the ADC maps and hyperintensity in the DWI-800. Twenty-three of the metastases showed peripheral hypointensity in the ADC maps and hyperintensity in the DWI-800. Nine of the metastases did not show hypointensity in ADC maps, and they were almost entirely necrotic. The abscesses were hypointense in the ADC maps and hyperintense in the DWI-800. The THADs and the focal fatty infiltration were isointense in the ADC maps and in the DWI-800. Features of all lesions in DWI evaluation are presented in Table 2.

According to the reference standard, 35 (33.33\%) of all lesions were malignant, and $70(66.66 \%)$ were benign. According to the DWI evaluation, 30 (28.5\%) of all lesions were malignant, and 75 (7l.4\%) of them were benign (Table 3 ). The results derived from this table were as follows (the values in brackets are $95 \%$ confidence interval): sensitivity: $74.29 \%$ (56.75\%-87.51\%), specificity: 94.29\% (86.01\%-98.42\%), positive predictive value: $86.67 \%$ (71.10\%-94.50\%), negative predictive value: $88.00 \%(80.63 \%-92.81 \%)$, and accuracy: $87.62 \%$ (79.76\%-93.24\%). 


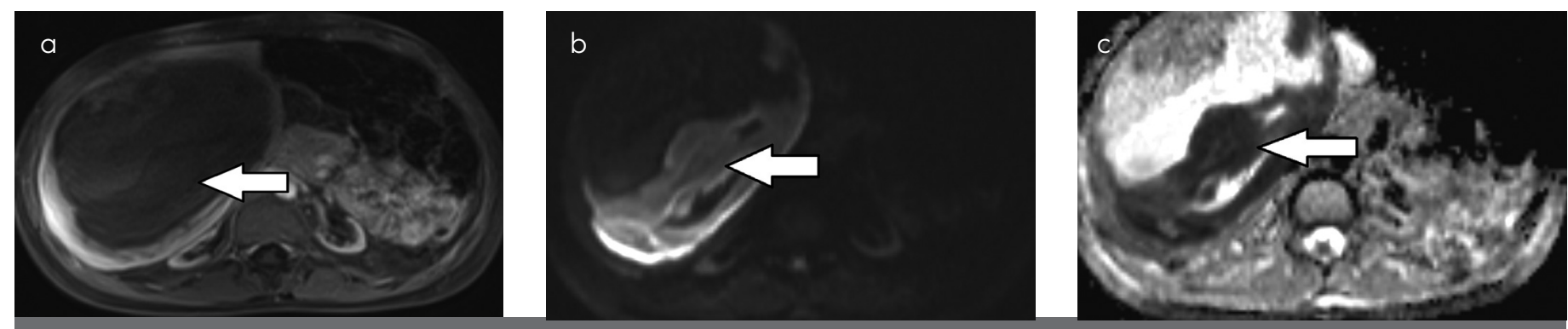

FIGURE 7. a-c. A very large lesion measuring $14 \mathrm{~cm}$ in the right liver lobe of a patient does not show contrast enhancement in the portal venous phase (a) where there is hyperintensity on b800 image (b) and hypointensity on ADC map (c), because of the effects of blood products
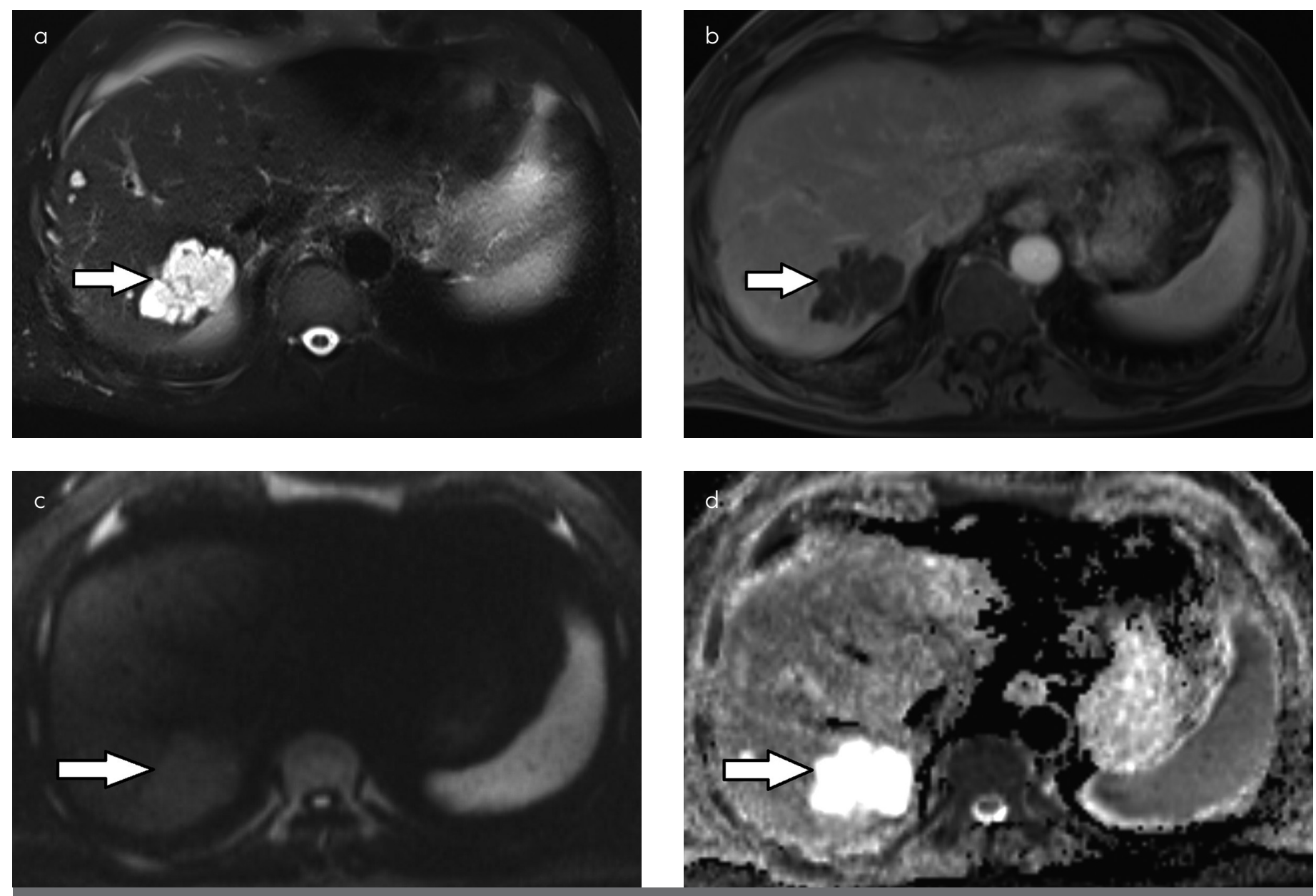

FIGURE 8. a-d. A necrotic metastasis. The lesion has septa on the T2-weighted image (a) and slight contrast enhancement on these septas on venous phase (b). It is slightly hyperintense on b800 (c) and obviously hyperintense on ADC map (d)

No malignant FLL was found in six patients with primary malignancy. Four of them had hemangiomas, one had a simple cyst, and one had an adenoma. In this respect, the DWI-alone interpretation was adequate to classify benign FLLs in patients with malignancy. In 28 patients without known malignancy, all FLLs were accurately interpreted as benign in the DWI-alone interpretation. The DWI-alone interpretation was accurate about 52 lesions in this group (Table 4). Only four lesions were misinterpreted as malignant in the DWI-alone interpretation. Three of these lesions were abscesses, and one of them was a hemorrhagic adenoma (Figure 6, 7). Only one patient without known malignancy had a malignant lesion, and it was an HCC. The DWI-alone interpretation was able to detect this HCC and classified as a malignant lesion. In the
DWI-alone interpretation, nine lesions were misinterpreted as benign although they were malignant. All of these lesions were found in the livers of previously known malignancy patients, and they were diagnosed as necrotic metastases (Figure 8).

\section{DISCUSSION}

According to our results, upper abdominal MRI studies of 28 of 32 patients ( $87.5 \%$ ) without known primary malignancy could be classified as benign or malignant with only signal characteristics on DWI sequences. All benign lesions in these patients were accurately classified by the DWI, which means that these MRI studies could have been completed without additional sequences and iv contrast media. These lesions were either 
hyperintense or isointense in the ADC maps because of the absence of diffusion restriction and were classified as benign by visual assessment. In the formation of the DWI, density of atoms and TI and T2 time differences of a tissue are influential $(19,24)$. In diffusion-weighted images with low b-values, the cystic or liquid components of tissues may have a high T2 effect ( $T 2$ shine-through effect). But in images with high b-valves, this effect diminishes and the signal intensity highly depends on cellularity (25). Factors causing restriction of diffusion have been implicated to differences in cellularity, necrosis, nucleus/cytoplasm ratios, viscosity, and perfusion status (2630). Tightly and randomly arrayed cells hinder the movement of extracellular water molecules. The increased cellularity of a tissue and the integrity of cell membranes are inversely proportional to the free diffusion of water molecules $(26,27)$. In addition, the movement of intracellular water molecules is restricted in tumors with high nucleus/cytoplasm ratio $(26,31)$. In the remaining four patients without known malignancy, the lesions were a hemorrhagic adenoma, three abscesses, and one HCC. These lesions were hypointense in the ADC maps suggesting restricted diffusion. Diffusion restriction of malignant tumors is the result of their high cellularity and smaller cell size as in the HCCs (32). Despite being benign, diffusion restriction in abscesses is associated with high viscous fluid containing large proteins, bacteria, and inflammatory cells that resist movement of molecules (30). Partial hypointensity of the hemorrhagic adenoma in the ADC map may be attributed to magnetic susceptibility effects of hemoglobin products (33). In our study, detection of malignant lesions by DWI evaluation was performed with $74.29 \%$ sensitivity and $88 \%$ negative predictive values. These values are relatively low for a screening test for patients with cancer. When we examined the cause of this, we found that false negative lesions according to the DWI-alone interpretation were the necrotic metastases under chemotherapy. These lesions were hyperintense or isointense in the ADC maps. Solid areas of these lesions that could restrict diffusion were almost vanished (34). They had only thin enhancing walls or septa. For this reason, we think that DWI imaging alone is not adequate especially in patients with known malignancy under treatment.

There are articles suggesting to use liver DWI for the detection of lesions and then subsequent characterization of lesions with iv contrast-enhanced $\mathrm{TI}$-weighted sequences rather than using DWI alone (35). In this study, we did not intended to characterize the FLLs but classifying them as benign or malignant to eliminate iv contrast use and additional sequences.

The main difficulty in classifying FLLs with DWI is the differentiation of solid benign lesions (especially FNHs and adenomas) from malignant lesions $(8,36)$. FNHs and adenomas of liver are relatively rare according to the simple hepatic cysts and hemangiomas $(37,38)$. According to the data obtained from our study, the diagnosis of liver cysts and hemangiomas can mostly be made with DWI. In a study conducted by Girometti et al. (23) comparing visual assessment of ADC maps and quantification of ADC value to differentiate benign and solid lesions, accuracy of both methods was limited. We consider that the reason for this result is excluding hemangiomas and cysts from the study and analyzing only solid lesions. We included hemangiomas and cysts in our study since these lesions are common and may not be able to precisely diagnosed by US in patients with fatty liver or in conditions such as obesity and meteorism (39). Kenis et al. (40) found that visual assessment of DWI alone had the same performance as contrast-enhanced MRI in their study investigating the diagnosis of liver metastases in 68 patients. We think that visual assessment of DWI alone is sufficient for demonstrating benign features of common incidental FLLs in majority of cases. To do this, a radiologist must initially interpret the DWI images, and a decision must be made whether the examination should continue.

The limitations of our study are relatively low benign solid lesion diversity and lack of pathology reports in all solid lesions. Except one, biopsy was not required in patients without known malignancy because MRI findings and follow-up examinations were enough to show that the lesions were benign. In a patient with cirrhosis, the diagnosis of an HCC was straightforward depending on the detection of wash-out in contrast-enhanced sequences. In patients with previously known malignancy, the metastatic lesions were diagnosed by detecting peripheral halo type enhancement, contrast loss in late phases compared to normal liver parenchyma, nuclear medicine imaging results, and size changes because of treatment status. The diagnosis of benign lesions in these patients was made as in the patients without known malignancy, and no biopsy was required.

In summary, benign features of an FLL detected in a patient without known malignancy in modalities other than MRI can be shown using DWI alone. DWI is also capable of detecting malignant lesions in patients with or without known malignancy. However, it is not a suitable method for screening necrotic metastases under treatment. In appropriately selected patients, a liver MR examination can be completed with only DWI. This will contribute to reducing workload, allocating more time to the requiring patients, and reducing contrast agent usage and costs. A disadvantage of this practice is the need for a radiologist's interpretation for the decision whether to continue scan.

In conclusion, starting the upper abdominal MRI studies with DWI seems to be a practical approach to the management. We believe that researches from this perspective having more patients and more diverse lesions will make this opinion more acceptable.

Ethics Committee Approval: Ethics committee approval was received for this study from Near East University Ethics Committee for Scientific Researches.

Informed Consent: Informed consent was not taken due to retrospective design of the study.

Peer-review: Externally peer-reviewed.

Author contributions: Concept - S.G.; Design - S.G.; Supervision - M.K.; Resource - M.K., S.G.; Materials - S.G., M.K.; Data Collection and/or Processing - S.G.; Analysis and/or Interpretation - M.K.; Literature Search - S.G.; Writing - S.G.; Critical Reviews - M.K. 
Conflict of Interest: The authors have no conflicts of interest to declare.

Financial Disclosure: The authors declared that this study has received no financial support.

\section{REFERENCES}

I. Chen L, Liu M, Bao J, Xia Y, Zhang J, Zhang L, et al., The correlation between apparent diffusion coefficient and tumor cellularity in patients: a meta-analysis. PLoS One 2013; 8: e79008. [CrossRef]

2. Xia $D$, Jing J, Shen $H$, and Wu J. Value of diffusion-weighted magnetic resonance images for discrimination of focal benign and malignant hepatic lesions: a meta-analysis. J Magn Reson Imaging 2010; 32: 130-7. [CrossRef]

3. Peng J, Li JJ, Li J, Li HW, Xu GP, Jia RR, et al. Could ADC values be a promising diagnostic criterion for differentiating malignant and benign hepatic lesions in Asian populations: A meta-analysis. Medicine (Baltimore) 2016; 95: e5470. [CrossRef]

4. Cieszanowski A, Anysz-Grodzicka A, Szeszkowski W, Kaczynski B, Maj E, Gornicka B, et al. Characterization of focal liver lesions using quantitative techniques: comparison of apparent diffusion coefficient values and T2 relaxation times. Eur Radiol 2012; 22: 25I4-24. [CrossRef]

5. Bruegel M, Holzapfel K, Gaa J, Woertler K, Waldt S, Kiefer B, et al. Characterization of focal liver lesions by ADC measurements using a respiratory triggered diffusion-weighted single-shot echo-planar MR imaging technique. Eur Radiol 2008; 18: 477-85. [CrossRef]

6. Demir Ol, Obuz F, Sagol O, Dicle O. Contribution of diffusion-weighted MRI to the differential diagnosis of hepatic masses. Diagn Interv Radiol 2007; 13: 81-6.

7. Filipe JP, Curvo-Semedo L, Casalta-Lopes J, Marques MC, Caseiro-Alves F. Diffusion-weighted imaging of the liver: usefulness of $A D C$ values in the differential diagnosis of focal lesions and effect of ROI methods on ADC measurements. MAGMA 2013; 26: 303-12. [CrossRef]

8. Miller FH, Hammond N, Siddiqi AJ, ShroffS, Khatri G, Wang Y, et al. Utility of diffusion-weighted MRI in distinguishing benign and malignant hepatic lesions. J Magn Reson Imaging 2010; 32: 138-47. [CrossRef]

9. Onur MR, Cicekci M, Kayali A, Poyraz AK, Kocakoc E. The role of ADC measurement in differential diagnosis of focal hepatic lesions. Eur J Radiol 2012; 8I: el7I-6. [CrossRef]

10. Vermoolen MA, Kwee TC, and Nievelstein RA. Apparent diffusion coefficient measurements in the differentiation between benign and malignant lesions: a systematic review. Insights Imaging 2012; 3: 395-409. [CrossRef]

II. Bharwani N, Koh DM. Diffusion-weighted imaging of the liver: an update. Cancer Imaging 2013; 13: 17|-85. [CrossRef]

12. Kocaoglu M, Bulakbasi N, Sanal HT, Kismet E, Caliskan B, Akgun V, et al. Pediatric abdominal masses: diagnostic accuracy of diffusion weighted MRI. Magn Reson Imaging 20I0; 28: 629-36. [CrossRef]

13. Battal B, Kocaoglu M, Akgun V, Karademir I, Deveci S, Guvenc I, et al. Diffusion-weighted imaging in the characterization of focal liver lesions: efficacy of visual assessment. J Comput Assist Tomogr 2011; 35: 326-31. [CrossRef]

14. Vilanova JC, Barcelo J, Smirniotopoulos JG, Perez-Andres R, Villalon M, Miro J, et al., Hemangioma from head to toe: MR imaging with pathologic correlation. Radiographics 2004; 24: 36785. [CrossRef]

15. Danet IM, Semelka RC, Leonardou P, Braga L, Vaidean G, Woosley JT, et al. Spectrum of MRI appearances of untreated metastases of the liver. AJR Am J Roentgenol 2003; 18I: 809-17. [CrossRef]

16. Elsayes KM, Narra VR, Yin Y, Mukundan G, Lammle M, Brown JJ. Focal hepatic lesions: diagnostic value of enhancement pattern approach with contrast-enhanced 3D gradient-echo MR imaging. Radiographics 2005; 25: 1299-320. [CrossRef]
17. Hussain SM, Zondervan PE, JN IJ, Schalm SW, de Man RA, Krestin GP. Benign versus malignant hepatic nodules: MR imaging findings with pathologic correlation. Radiographics 2002; 22: 1023-36. [CrossRef]

18. Willatt JM, Hussain HK, Adusumilli S, Marrero JA, MR Imaging of hepatocellular carcinoma in the cirrhotic liver: challenges and controversies. Radiology 2008; 247: 31I-30. [CrossRef]

19. Chan JH, Tsui EY, Luk SH, Fung AS, Yuen MK, Szeto ML, et al. Diffusion-weighted MR imaging of the liver: distinguishing hepatic abscess from cystic or necrotic tumor. Abdom Imaging 200l; 26: 161-5. [CrossRef]

20. Colagrande S, Centi N, Galdiero R, and Ragozzino A. Transient hepatic intensity differences: part 2, Those not associated with focal lesions. AJR Am J Roentgenol 2007; 188: 160-6. [CrossRef]

21. Jang JK, Jang HJ, Kim JS, and Kim TK. Focal fat deposition in the liver: diagnostic challenges on imaging. Abdom Radiol (NY) 2017; 42: 1667-78. [CrossRef]

22. Venkataraman $S$, Braga $L$, and Semelka RC. Imaging the fatty liver. Magn Reson Imaging Clin N Am 2002; 10: 93-103. [CrossRef]

23. Girometti R, Del Pin M, Pullini S, Cereser L, Como G, Bazzocchi M, et al. Accuracy of visual analysis vs. apparent diffusion coefficient quantification in differentiating solid benign and malignant focal liver lesions with diffusion-weighted imaging. Radiol Med 2013; II8: 343-55. [CrossRef]

24. Eastwood JD, Engelter ST, MacFall JF, Delong DM, Provenzale JM. Quantitative assessment of the time course of infarct signal intensity on diffusion-weighted images. AJNR Am J Neuroradiol 2003; 24: 680-7.

25. Colagrande S, Belli G, Politi LS, Mannelli L, Pasquinelli F, Villari N. The influence of diffusion- and relaxation-related factors on signal intensity: an introductive guide to magnetic resonance diffusion-weighted imaging studies. J Comput Assist Tomogr 2008; 32: 463-74. [CrossRef]

26. Norris DG. The effects of microscopic tissue parameters on the diffusion weighted magnetic resonance imaging experiment. NMR Biomed 200I; 14: 77-93. [CrossRef]

27. Lang P, Wendland MF, Saeed M, Gindele A, Rosenau W, Mathur A, et al. Osteogenic sarcoma: noninvasive in vivo assessment of tumor necrosis with diffusion-weighted MR imaging. Radiology 1998; 206: 227-35. [CrossRef]

28. Gauvain KM, McKinstry RC, Mukherjee P, Perry A, Neil JJ, Kaufman BA, et al. Evaluating pediatric brain tumor cellularity with diffusion-tensor imaging. AJR Am J Roentgenol 200I; 177: 449-54. [CrossRef]

29. Sugahara T, Korogi Y, Kochi M, Ikushima I, Shigematu $Y$, Hirai T, ef al. Usefulness of diffusion-weighted MRI with echo-planar technique in the evaluation of cellularity in gliomas. J Magn Reson Imaging 1999; 9: 53-60. [CrossRef]

30. Ebisu T, Tanaka C, Umeda M, Kitamura M, Naruse S, Higuchi T, et al. Discrimination of brain abscess from necrotic or cystic tumors by diffusion-weighted echo planar imaging. Magn Reson Imaging 1996; |4: III3-6. [CrossRef]

31. Kotsenas AL, Roth TC, Manness WK, Faerber EN. Abnormal diffusion-weighted MRI in medulloblastoma: does it reflect small cell histology? Pediatr Radiol 1999; 29: 524-6. [CrossRef]

32. Gluskin JS, Chegai F, Monti S, Squillaci E, and Mannelli L. Hepatocellular Carcinoma and Diffusion-Weighted MRI: Detection and Evaluation of Treatment Response. J Cancer 2016; 7: 1565-70. [CrossRef]

33. Kang BK, Na DG, Ryoo JW, Byun HS, Roh HG, Pyeun YS. Diffusion-weighted MR imaging of intracerebral hemorrhage. Korean J Radiol 200I; 2: I83-91. [CrossRef]

34. Scurr ED, Collins DJ, Temple L, Karanjia N, Leach MO, Koh DM. Appearances of colorectal hepatic metastases at diffusion-weighted MRI compared with histopathology: initial observations. Br J Radiol 2012; 85: 225-30. [CrossRef] 
35. Mannelli L, Bhargava P, Osman SF, Raz E, Moshiri M, Laffi G, et al. Diffusion-weighted imaging of the liver: a comprehensive review. Curr Probl Diagn Radiol 2013; 42: 77-83. [CrossRef]

36. Girometti R, Del Pin M, Pullini S, Cereser L, Como G, Bazzocchi $M$, et al. Does diffusion-weighted imaging add diagnostic confidence in discriminating between benign and malignant solid focal liver lesions? Clin Imaging 20I4; 38: I36-4I. [CrossRef]

37. Bartolozzi C, Cioni D, Donati F, Lencioni R. Focal liver lesions: MR imaging-pathologic correlation. Eur Radiol 200I; II: 1374-88. [CrossRef]
38. Lantinga MA, Gevers TJ, and Drenth JP. Evaluation of hepatic cystic lesions. World J Gastroenterol 2013; 19: 3543-54. [CrossRef]

39. Vilgrain V, Boulos L, Vullierme MP, Denys A, Terris B, Menu Y Imaging of atypical hemangiomas of the liver with pathologic correlation. Radiographics 2000; 20: 379-97. [CrossRef]

40. Kenis C, Deckers F, De Foer B, Van Mieghem F, Van Laere S, Pouillon $M$. Diagnosis of liver metastases: can diffusion-weighted imaging (DWI) be used as a stand alone sequence? Eur J Radiol 2012; 81: 1016-23. [CrossRef] 